\title{
The Data of Nations
}

'This is a long term play. The idea is that in the future there is no human interaction. There is just a machine that knows you and what you're asking and what you like.'

Marc Lore cited by Dumaine p 191

Executive Vice-President Margrethe Vestager, in charge of competition policy, said:

'We must ensure that dual role platforms with market power, such as Amazon, do not distort competition. Data on the activity of third party sellers should not be used to the benefit of Amazon when it acts as a competitor to these sellers. The conditions of competition on the Amazon platform must also be fair. Its rules should not artificially favour Amazon's own retail offers or advantage the offers of retailers using Amazon's logistics and delivery services. With e-commerce booming, and Amazon being the leading e-commerce platform, a fair and undistorted access to consumers online is important for all sellers.'

Press Release European Commission 10 November 2020 
We might start by going back to what the deal actually is between the client and Amazon and the role of algorithms in it. The deal might best be seen, in its first form, in the joining of a club. The club is a data club, the most extensive in the world with the best farmers of data, the best algorithms. The key club, the main portal, if you like, is Prime. We go through the club doors to a rewards programme. This morphs and spins into a universe of power and control. Data is potential power and the algorithms are ways of realising control of that power.

As Dumaine (Dumaine 2020: 216) says Amazon has unparalleled technological firepower. The flywheel is driven by massive amounts of data. Who owns data? Amazon owns all pricing and product data going through its platform. The adage that knowledge is power takes on another sense.

The data of nations is in Amazon. If data is money Amazon is a major bank- amongst its data peers like the World Bank in terms of currency perhaps. Control of the data and its processing, of the action on the grid, if you like is contested in The German Example and in the comments by Margrethe Vestager from the European Union above. These are both examples of what I have called the Political Cap where a state or set of states has set limits on Amazon. The question or challenge for the algorithms is how to learn to get around the constraints called for by, say, the German government.

Sometimes the answers to such questions and challenges come in a crisis. We think of Gates in the Ebola crisis and Amazon in the current pandemic. At what point in the pandemic might market conditions change? And what solutions might the algorithms of Amazon provide on the German Example in the meantime?

The argument here, as always or at least most often, is about wealth. The phrase, 'the data of nations' follows 
Adam Smith's The Wealth of Nations (1776). If data is wealth then it's all about how you use that wealth and that is where the algorithms matter. Where the British administration of, say, India or the Dutch administration of their mercantile empire depended on the training and attitude of personnel in the field and at home, this is a matter of knowing the best ways to use robotics and cobotics now.

To put this another way, could Amazon withhold or control data in such a way as to influence nation-states?

The German Example represents a world order. One country sets in motion a decree that applies across nations. This would seem to call for a review of arrangements with states. There is the arrangement that Amazon has with the Pentagon which might be described as unilateral. When it comes to arrangements with entities like the EU we might have a multilateral situation. The German Example represents or is meant to indicate a loss; Amazon cannot shut down a competing product. The Singaporean-Indian Example indicates a win. Amazon cannot be factored out of the Indian market according to a Singaporean Judge. But each of these examples is just another ordering to be measured, learnt and maximised by the algorithms involved. We get to wonder...the order might be of a value in the world, of a 'win' or of a 'loss' and then again it might be of an equation in the algorithm. The order of things is simply a challenge for the algorithm to process, meet and learn from.

But we might also come to think about a situation outside of states as they are known on earth. For example the creation of a set of satellites above the earth providing internet and other services may be seen as an exoskeleton outside and away from state, interstate and state and business interaction. If the data is collected and shared by a web of entities outside the space and air of the earth 
then even the phrase, 'the data of nations', starts to lose force.

Like a lot of things discussed above it often comes back to scale. Most things about Amazon can be copied like say the management systems such as the six pager etc but data is capital and Amazon has data of scale. Coming back to Geoffrey West's book Scale (2017) the real trick with scale is to have data and the capacity to use it.

Then there is the comprehension of scale. To the edge of a country? To the edge of a space? If we think of Amazon in terms of sovereignty, to the edge of a realm? To the edge of space itself? Or to a set limit to an algorithm? We might think of the algorithm as being without set anchors, without a state capital or government to defer to except as an occasional obstacle.

Is the key pairing here between Amazon and the client, between the algorithm and the client or simply between algorithms? Cobot to robot, cobot to cobot or robot to robot? This takes us back to the consideration of agency. If the key pairing is cobot to cobot we may be at the point where the machine leads the dance and if the key pairing is robot to robot humans might watch the dance from their consumer farm. If the key matter is happiness then, after Huxley (1998), Hsieh (2013) and others we smile as we watch or join the dance. If the key matter is memory, social memory, then, after Foote (2003), Min (2018) and others we may be jogged into a sense pf past, present and future by the dates, by the shapes of time we are fed.

How much of all this is rationalisation? For example the US has four times the store space of other rich nations (Dumaine ibid166). So a lot of what is happening may simply be a recognition of waste, wasted space in this case. At the same time rationalisation and change might happen in a variety of ways. There is the space of the 
shop, the space of the warehouse, the space of the country and with drones the space of the sky.

And then there is space as in outer space. Bezos, Amazon and the algorithms associated are in all of these spaces and rationalising, as it were, one in terms of or against another. Regarding data the issue might be where it is stored. If it is stored in outer space in satellites then we are outside of nation-states just as we are outside of the earth. The data of nations becomes an obsolete phrase perhaps.

As Jack Ma says all companies become tech companies in this context. Retailers will also need to be tech companies as the algorithm is king as Dumaine points out (ibid 205). At the same time the limits of tech are evident- data and AI. How much data and what forms of capture, control and advancement exist for each company?

Then there is a question of data and experience. Nike is maximising personal experience both in-store and online. Luxury brands may compete with Amazon but not mass brands. We might ask on the one hand how long can the buying experience be a factor? On the other we might ask how long before Amazon masters the buying experience? Does Amazon have 'the eye of the merchant'? It's all about personalisation. Or is it? The Stitch Fit example where individual clothing needs are finely tuned and met seems out on its own. But is it and could Amazon beat it? It's a matter of curation as per Lulus. Or is it? All this may ultimately be a matter of patience and capital and Bezos' insistence on long term thinking may come into play here.

Dumaine speaks of the shopping experience as something in which Amazon may not compete effectively. Given Amazon's position in entertainment via Prime it is remarkable that this is the case. There is also the weight, 
the heft of Amazon as an idea, as a value, as something we trust which must have an effect. We might go back to the description of the King movement after land confiscation which is described above as a hub of ritual and concept, of metaphor and hope, of, in a word, trust and the question might be left hanging as to whether Amazon might emulate that.

Alexa offers an experiential, visceral presence of a kind that we do not yet know the dimensions of.

Like a lot of Amazon matters it's a matter of finding the dots and then connecting them or letting the algorithms find the connections and work out the agencies. Then it is a matter of consumer satisfaction. Over time. In a sense the algorithms themselves are the agencies to determine what is to be delivered and how, when and with a sense of satisfactory experience. The algorithms learn the consumers' needs and how, when and why they might be satisfied, robot to cobot as a new consumption cycle comes into being.

We might take the word satisfaction and think of it in terms of the literature on pleasure. As far back as 1985 Neil Postman contrasted the worlds of Nineteen EightyFour (1949) and Brave New World (1994) in the foreword of his book Amusing Ourselves to Death:

What Orwell feared were those who would ban books. What Huxley feared was that there would be no reason to ban a book, for there would be no one who wanted to read one. Orwell feared those who would deprive us of information. Huxley feared those who would give us so much that we would be reduced to passivity and egoism. Orwell feared that the truth would be concealed from us. Huxley feared the truth would be drowned in a sea of irrelevance. Orwell feared we would become a captive culture. Huxley feared we would become a trivial culture, preoccupied with some equivalent of 
the feelies, the orgy porgy, and the centrifugal bumblepuppy. As Huxley remarked in Brave New World Revisited, the civil libertarians and rationalists who are ever on the alert to oppose tyranny "failed to take into account man's almost infinite appetite for distractions." In 1984, Huxley added, people are controlled by inflicting pain. In Brave New World, they are controlled by inflicting pleasure. In short, Orwell feared that what we hate will ruin us. Huxley feared that what we love will ruin us.

Postman, 1985

And so, and in some kind of a conclusion we might start to define the algorithmic state as one where satisfaction, especially immediate satisfaction is critical. Bezos and Amazon have ridden a wave of satisfaction and so too have Jack Ma of Alibaba and Ant, JD and others.

We might think of algorithms and ecology with, again, apologies to Marshall Sahlins (Sahlins 1958). If the ecology were a high island then the algorithm has one set of mastery tasks. A low island might have another set of measurements, gaps to avoid or breaches to form. And then there is the plain, the open space with another set of options. At each point there is a different learning and a different maximisation of market to find and develop. And in each case there might be different power structures to accommodate.

We might think of the use of algorithms to process data in platforms and look at Bezos and space. There is the dream of a trillion people in space and there is the approaching reality of what has been described as an exoskeleton of satellites that low orbit the earth providing internet services. Given 
the realization of the Trillion Persons dream, these orbiting satellites become rather more than an exoskeleton around the earth. They become a new anchor, a new super hub which, for a moment anyway, might be 'home' or home base.

It is suggested here that there is a shapeshifter aspect to the Amazon experience now. The outfit is so powerful that an anchoring back to the earth as in the exoskeleton example above becomes an exploration point for space so that another anchoring point might be found out there somewhere and an inter-hub situation be developed. Incredible as it seems, Earth as a planet might simply be left behind or at least left as an original shape, an antique form.

Where Bezos and Amazon goes so does Eion Musk and Tesla- into space, soon, no doubt, to be followed by the inevitable and ubiquitous Jack Ma and Alibaba and Ant.

Here we have, on the face of it, a statelessness. The states of earth have been left behind. But perhaps the states of earth were already left behind with developments by these players and others in cyberspace. Perhaps, beyond the face there is an incipient form in a new kind of state to be.

Coming back to earth there may be a new form of multiplier in the relation between hub and algorithm. We have not done the learning yet about rationalising hubs in the most efficient way and we might go back to some of the questions Berry (1996) is asking about tourist and corporate travel regarding hubs as well as other questions. The algorithms will maximise hubs. What will happen to cities when and they are transformed by the Beehive concept with drones operating at the high 
levels of high rises (Venture City 1019). There is the obviation of roads for a start...

Then there is the classification of power places to use a phrase. The algorithmic state would be a series of linked hubs. How do we think of hubs? As mere warehouses or as critical points in an infrastructure of state? A most rudimentary typology of hubs has been offered here and it is important perhaps to note that algorithms operate inside hubs monitoring and directing workers (Hart 2019, Venture City 2019). A comprehensive typology of hubs could show the range and diversity of uses and activities involved and to come back to the idea of skeletons we might be seeing a redrawing of the body economic as well as the body politic in such a structure.

We might also be seeing a redrawing of the urban scene including the city. For example if we go back to the vision of a 'beehive'with shops on the ground floor and upper levels being access points for drones to fulfilment centres the thinking generally has been that this will simply be a use of high rises in cities, the 'anomaly' being that the Fulfilment Centres have been in rural areas away from towms so far. But there is no reason why the flat one story structures in the rural areas of the centres now are not simply built upon, layer by layer, to provide access points for the drones, the cities and high rises therein not being involved. And this is the vision in Hart's The Warehouse (ibid). The hubs stand alone outside of formerly normal urban or city based existence.

We then have questions of power. What are the deals about algorithms and who makes them? What are the deals with algorithms? What are the taxes on an algorithm? Looking ahead what might he ideal host state for an algorithm? How could algorithms learn about how to be hosts in a state-like situation? Is Amazon pioneering the algorithms for a host state? 
We could ask again about the membership fee in a rewards programme such as Prime. At what point does it become a tax? Is it just another factor for algorithmic consideration- a question of finding limits and tolerance for costs? At what point does membership become an entry point, a border for those within and those without a system? It is worth noting after Dumaine that the algorithms in Amazon work to member in and member out sellers in the market...

Do algorithms know scale? Or do they simply run to infinity? Bezos in the George W Bush lecture of 2018 plays down the idea of forms of AI that might set their own objectives.

Algorithms are geared to learn and to find the best environments, the most efficient grids. In terms of state sovereignty this is a random process. Its not about whether a democracy prevails in a certain context its about efficiency, pure and simple.

To what extent is Amazon cosmopolitan in the sense that Ulrich Beck (2000) uses the term to differentiate from a fixation with the nation state. Is that possible? Is it a conceit or a deceit to think that the edge of states are distinct from the centre of states and to claim cosmopolitanism as an alternate option? To an algorithm set to do so a nation state or a cosmopolitan situation offer possibilities to develop contexts of satisfaction, different beds of and for satisfaction regardless and in spite of locale.

We could look back at Coulon (1978) and his arguments about ethnicity in Jacobin France and look at Trump in the centre of America along with Walmart and say they are in a cluster, so to speak, of nationalism. And then at Amazon on the coast, apparently free as a bird to fly globally. 
Or are we looking at a situation where nation-states become merely physical entities in a geographical area with something altogether different binding people and committing them to membership as they are satisfied in another, new way? What does the machine say?

Again, it may pay to come back to the word 'state'.

As we talk terms it might be best to go with a caveat that a lot is not understood. By most if not all of us. We started with a consideration of the Maori King in New Zealand and to go back further than that to the signing of the Treaty of Waitangi the English had no or little idea of Maori notions of sovereignty, of state and nor did the English know of Maori concepts and actualities of governance. Here we might go back to the broad as well as the specific sense of Anne Salmond's Two Worlds (2018) and to the critique by Peter Munz (1994) of her work. The 'Two World's' distinction is tricky as can be seen in the critique by Buddy Mikaere (Mikaere 2017) of another book by Anne Salmond (Salmond 2017) and this is a problem when one world is only vaguely known. Salmond is accused again of missing things and finding characteristics.

In our time we know little of the world of the algorithm and that may be, of course a dangerous thing. We can miss lots and ascribe characteristics as we might attempt to describe that world. Here too there are two worlds, there is the world of algorithms and the world of people, here there is what has been described as a cobotic situation. Are both parties understood by one another? Are the understandings, the comprehensions, each of the other utterly different? Words fail, to some extent, as we are left with the epistemology of the machine to which, we think, we do not relate. And we do not know how the machines know us except as programme. 
And to some extent we confuse ourselves. If we were to turn again to the notion of the cosmopolitan we might pretend that it differs from a tight focus on a nation-state but actually we live in both without a clear idea of how to shed one of the other. Amazon and Bezos live, let's say, on the East and West Coasts of the USA while Walmart and Trump 'live' in the middle. But they are both in a shared America.

The ways we confuse or deceive or mislead ourselves might be explored. For example, I ask whether there is an effective historiography of technology. Our assumption has always been that machines are subordinate and all of politics and economics might be found in the human experience. But to write an effective history of the algorithm and its antecedents we might have to go back to Vaucansun's duck, to Voltaire's oblique, apparently offhand points about it and find a line of thought through the industrial revolution to Babbage and the rise of the computer with a nod to Wells (ibid) as well as to Huxley (ibid) along the way.

One strand of the argument here has been that Amazon offers a glimpse of a new consciousness a new sense of sovereignty perhaps, as people grapple with new conditions in a tired political state. This is a sovereignty game, a process of finding new political forms in the expiration of older ones. Amazon or at least the algorithms that it employs and that structure it are giving shape to this new consciousness. The game of sovereign chance where two groups entered the Treaty of Waitangi, each entering an unknown space applies to tension between cosmopolitanism and the nation state as it does to the notions of cobot and robot.

The difficulty is that sovereignty does not tend to mix with uncertainty. How might the current situation be seized upon or exploited? This will have to be left for another 
time but the situation is inchoate at present and could be difficult to work out for some time.

In the margins of this argument is the idea that China and Amazon are growing closer, neither of them democratic. The obvious point is that the grids that the algorithms are following in both cases are more efficient than those found elsewhere. And both parties know how to use one another as evinced by the number of Chinese operators using Amazon's platform both as producers and grand owners. In a sense Bezos is following $\mathrm{Ma}$ in running along China's tracks to take great liberties with a phrase from Lina Khan.

Is Bezos himself a cobot? At some point there is a need to disentangle personality and power if only for the sake of effective analysis. Bezos is in charge of Amazon which is to say that he is in charge of the data and algorithms involved. But then there are the shareholders. And then there are the managers of divisions. And then there are the algorithms which themselves set targets. The comments above from Vestager's appearance in an RT clip are significant in that Vestager, speaking for the European Union stresses the role of algorithms in determining what happens in competition on an Amazon sales site. Bezos is here and there in all of this but he is usually dependent upon or at least using extensively a robotic or algorithmic system of some kind. Is there something of a cult of personality now about Bezos, Ma and others and is it a kind of beard for the algorithm?

Coming back to the idea of the data of nations we might ask about data without nations which might be like wealth without nations and here it gets a little weird and beyond our current ken perhaps. We are used to the idea of such aspects of sovereignty as states owning forms of currency. 
We could come back to the idea of two suns with a question mark behind the phrase. In the first of these talks I referred to Governor Grey asking of the Maori King, 'Are there two suns in the sky?' We could look at Bezos and Trump and ask the same question which might take us to where Amazon might be located, in or out of the USA. Just as there was an argument cited above between Giancarlis and Carney there might be an argument about whether a given city such as New York in the USA is a good context for Amazon and its algorithms.

Similarly the two suns might be Jack Ma of Alibaba and Jeff Bezos of Amazon and a further set of questions ensue probably more to do with who has the best data and the best AI systems to deal with that data. This takes us back to the data of nations argument above.

And we might, at another level perhaps, ask whether the two suns are robot and cobot. Here we go to the literature and the movies with considerations of Alexa, with thoughts about Ex Machina (2014) and the book Living Dolls (Wood 2002) as entry points to such a discussion. 


\section{Bibliography}

Beck, Ulrich British Journal of Sociology No 51 Issue No 3 January/March 2000 pp 79-105

Berry, Steven, Carnall, Michael and Spiller, Pablo T, Airline Hubs, Costs, Markups and the Implications of Customer Heterogeneity National Bureau of Economic Research May 1996

Coulon, C 'French Political Science and Regional Diversity', in Ethnic and Racial Studies ed. Stone Vol 1 No 2 January 1978

Dumaine, Brian Bezonomics How Amazon is changing our lives and what the world is learning from it, Simon and Schuster 2020

Hart, Rob The Warehouse Bantam Press 2019

Huxley, Aldous Brave New World, Harper Collins 1998

Hsieh, Tony Delivering Happiness, Grand Central Publishing 2013)

Khan, Lina M. Amazon's Antitrust Paradox The Yale Law Journal 2017: 710-805

Min, Li Social Memory and State Formation in Early China, Cambridge University Press 2018

Munz, Peter 'The Two Worlds of Anne Salmond in Postmodern Fancy-Dress', New Zealand Journal of History, 28, 1 (1994).

Orwell, George Nineteen Eighty Four. A Novel, Secker and Warburg 1949

Sahlins, Marshall Social Stratification in Polynesia. Monographs of the American Ethnological Society, 29. Seattle: University of Washington Press, 1958

Salmond, Anne Two Worlds First Meetings Between the Maori and the Pakeha 1642-1772 Penguin 2018

Salmond, Anne Tears of Rangi: Experiments Across Worlds, Auckland University Press

Adam Smith's The Wealth of Nations, Strahan and Cadell 1776

West, Geoffrey Scale, The Universal laws of Life, Growth, and Death in Organisms, Cities and Companies, Penguin 2017 
Wood, Gaby Living Dolls, A Magical History of the Quest for Mechanical Life Faber and Faber 2002

\section{Internet and Movie References}

Mikaere, Buddy 'It turns our tupuna into cardboard caricatures': Buddy Mikaere reviews Anne Salmond $2017^{\prime}$

https: / thespinoff.co.nz/books / 22-11-2017/it-turnsour-tipuna-into-cardboard-caricatures-buddymikaere-reviews-anne-salmond/

RT EU launches antitrust probe of Amazon Nov 112020 https://www.youtube.com/watch?v=F4DaYSCIa2M

Venture City Amazon's City of the Future Nov 72019 Youtube

Ex Machina movie, Universal Pictures 2014 